\title{
Bipolar disorder recurrence prevention using self-monitoring daily mood charts: case reports from a 5 year period
}

This article was published in the following Dove Press journal:

Neuropsychiatric Disease and Treatment

7 March 2017

Number of times this article has been viewed

\author{
Norio Yasui-Furukori \\ Kazuhiko Nakamura \\ Department of Neuropsychiatry, \\ Graduate School of Medicine, \\ Hirosaki University, Hirosaki, Japan
}

\begin{abstract}
Mood symptoms in bipolar disorders are significantly related to psychosocial events, and the personalized identification of symptom triggers is important. Ecological momentary assessments have been used in paper-and-pencil form to explore emotional reactivity to daily life stress in patients with bipolar disorder. However, there are few data on long-term recurrence prevention effects using ecological momentary assessments. Subjects were three outpatients with bipolar disorder who had a history of at least one admission. They recorded self-monitoring daily mood charts using a 5-point Likert scale. Paper-and-pencil mood charts included mood, motivation, thinking speed, and impulsivity. Additionally, they recorded waking time, bedtime, and medication compliance. Fewer manic or depressive episodes including admissions occurred after self-monitoring daily mood charts compared to patients' admissions in the past 3 years. This study suggests that self-monitoring daily mood in addition to mood stabilizing medication has some effect on recurrence prevention in follow-up periods of at least 5 years. Further studies with rigorous designs and large sample sizes are needed.
\end{abstract}

Keywords: bipolar disorders, recurrence, self-monitoring, ecological momentary assessments

\section{Introduction}

Bipolar disorders are chronic conditions with lifetime prevalence rates of $0.6 \%$ for bipolar I and $0.4 \%$ for bipolar II. ${ }^{1}$ Although bipolar disorders have a strong genetic etiology, ${ }^{2}$ mood symptoms are significantly related to psychosocial events. ${ }^{3}$ Thus, the personalized identification of individual psychosocial triggers is important to manage bipolar disorders.

Studies of bipolar symptomatology often rely on self-report measures and fixedinterval weekly to monthly assessments, ${ }^{4}$ but this approach is limited by recall bias. Several studies suggest that retrospective self-ratings are strongly affected by peak moments. ${ }^{5}$ Because of these limitations, there is growing interest in the self-monitoring of mood and behavior on a daily basis. This monitoring includes observations of progression into episodic depressive or manic states. ${ }^{6-8}$ Ecological momentary assessments involving repeated sampling of subjects' current behaviors and experiences in real time and in subjects' natural environments have been used in several studies. ${ }^{7-9}$ This aims to minimize recall bias and maximize ecological validity. The ecological momentary assessments have been used in paper-and-pencil form to explore emotional reactivity to daily life stress among participants with affective disorder including bipolar disorders. ${ }^{8}$ Frequent self-monitoring of symptomology associated with bipolar disorders including prodromal symptoms would allow psychiatrists to personalize treatment approaches in a more timely manner. ${ }^{8}$
Correspondence: Norio Yasui-Furukori Department of Neuropsychiatry, Graduate School of Medicine, Hirosaki University, Zaifucho 5, Hirosaki, Aomori 036-8562, Japan Tel +8I I72 395066 Fax +8I I72 395067 Email yasufuru@hirosaki-u.ac.jp 
However, because the observation periods were less than 6 months in most studies, ${ }^{8}$ there are few data about long-term recurrence prevention effects using ecological momentary assessments. Therefore, we reported three cases using self-monitoring daily mood charts to prevent recurrence episodes in higher risk individuals with bipolar disorders. We conducted the present study after obtaining approval from the Ethics Committee at the Hirosaki University School of Medicine. Participants provided written informed consent after receiving a full description of the study and consented for the report to be published.

\section{Cases}

\section{Case I}

The patient was a 43-year-old Japanese male with a 6-year history of type I bipolar disorder with four admissions for a mixed state. He was treated with $100 \mathrm{mg} / \mathrm{d}$ of amoxapine, $30 \mathrm{mg} / \mathrm{d}$ of mirtazapine, and $5 \mathrm{mg} / \mathrm{d}$ of nitrazepam for more than 6 months. He was transferred to our hospital because of the poor control of his mental state. His medication was changed to $400 \mathrm{mg} / \mathrm{d}$ of lithium and $75 \mathrm{mg} / \mathrm{d}$ of quetiapine. He recorded his moods using a 5-point Likert scale ranging from -2 , not at all happy, to 2, extremely happy, and paper-and-pencil mood charts including mood, motivation, thinking speed, and impulsivity. He recorded waking time and bedtime, and medication check, in addition to the four moods (Figure 1). The patient submitted self-monitored mood charts every 2 weeks at each visit. The patient and psychiatrist discussed associations between mood and daily event or sleep-wake rhythms and looked for any patterns. In addition, the psychiatrist reported if he noticed any subclinical and prodromal depressive or manic moods and prescribed an order-made coping style for them. We made three copies of the self-monitoring mood charts and delivered them to the patient, his wife, and a manager at his job at the end of each visit. All of the original mood charts were kept with his medical chart. He made daily routines and decided on a final goal. Following monitoring of his ecological statements and case management, his psychiatric symptoms improved, and 1 year later, he returned to work and continued working at his job. He has continued the self-monitoring daily mood charts for more than 7 years, and his mental state has remained stable (Table 1). He visits us at a 6-week interval.

\section{Case 2}

The patient was a 38-year-old Japanese female with a 5-year history of type I bipolar disorder with admission of three times because of a manic state. Because the patient had exhibited aggressive behavior toward her parents, she was treated with $800 \mathrm{mg} / \mathrm{d}$ of lithium, $800 \mathrm{mg} / \mathrm{d}$ of valproate, $9 \mathrm{mg} / \mathrm{d}$ of aripiprazole, and $4 \mathrm{mg} / \mathrm{d}$ of flunitrazepam. In addition to self-monitoring daily mood charts, as described in Case 1, medication dosing was checked, and wake-up time, bedtime, medication time, and body weight were recorded.

Self-monitoring daily mood charts

\begin{tabular}{|c|c|c|c|c|c|c|c|c|c|c|}
\hline \multirow[t]{2}{*}{ Date } & \multirow[t]{2}{*}{ Day } & \multicolumn{5}{|c|}{ Likert scale score } & \multirow[t]{2}{*}{ Wake-up time } & \multirow[t]{2}{*}{ Bedtime } & \multirow[t]{2}{*}{ Pill } & \multirow[t]{2}{*}{ Remarks } \\
\hline & & -2 & -1 & 0 & 1 & 2 & & & & \\
\hline November 9 & Monday & & $\nabla$ & $\Delta O \mathbf{m}$ & & & 0600 & 2300 & $\square$ & Nothing special \\
\hline November 10 & Tuesday & & & $\Delta O \mathbf{D}$ & & & 0610 & 2330 & $\square$ & Nothing special \\
\hline November 11 & Wednesday & & 口 & $\Delta \bigcirc$ & $\nabla$ & & 0550 & 0000 & $\square$ & Nothing special \\
\hline November 12 & Thursday & & $\mathrm{O}$ & $\Delta$ & $\nabla$ & & 0530 & 0120 & $\mathrm{X}$ & Overtime work \\
\hline November 13 & Friday & $\boldsymbol{\Delta \Delta}$ & $\mathrm{O}$ & & & $\nabla$ & 0620 & 0040 & $\mathrm{X}$ & Overtime work \\
\hline November 14 & Saturday & $\boldsymbol{\Delta \Delta}$ & $\mathrm{O}$ & & & $\boldsymbol{\nabla}$ & 0800 & 0230 & $\square$ & Drunk a lot \\
\hline November 15 & Sunday & & $\mathrm{O}$ & $\Delta$ & $\nabla$ & & 0830 & 0030 & $\square$ & 10 km running \\
\hline November 16 & Monday & $\mathrm{O}$ & 日 & $\Delta \nabla$ & & & 0710 & 2310 & $\square$ & Nothing special \\
\hline November 17 & Tuesday & 0 & $\Delta \mathbf{E}$ & $\Delta \square \nabla$ & & & 0620 & 2330 & $\square$ & Dinner with family \\
\hline November 18 & Wednesday & & $\mathrm{O}=$ & $\Delta \nabla$ & & & 0620 & 2330 & $\square$ & Nothing special \\
\hline November 19 & Thursday & & $\mathrm{O}$ & $\mathbf{\nabla}$ & $\Delta$ & & 0600 & 0050 & $\triangle$ & Nothing special \\
\hline November 20 & Friday & & $\mathrm{O}$ & $\Delta \nabla$ & & & 0530 & 0250 & $\square$ & Dinner with family \\
\hline November 21 & Saturday & & & $\Delta \bigcirc \boldsymbol{\nabla}$ & 口 & & 0540 & 2310 & $\square$ & $5 \mathrm{~km}$ running \\
\hline November 22 & Sunday & & & $\Delta \nabla \nabla$ & $\mathrm{O}$ & & 0550 & 2330 & $\square$ & $10 \mathrm{~km}$ running \\
\hline
\end{tabular}

Figure I Example of self-monitoring daily mood charts in patient I.

Notes: The patient recorded his moods using paper-and-pencil mood charts, which included mood, motivation, concentration, and impulsivity, and using a 5-point Likert scale ranging from -2 , not at all happy, to 2, extremely happy. He recorded waking time and bedtime, whether medication was taken, in addition to the four moods. The authors explained that between $-\mathrm{I}$ and I was considered a normal mood swing and -2 and 2 an abnormal swing. $\mathbf{\Delta}$ : Mood, O: Motivation, $\mathbf{\square}$ : Thinking speed, $\mathbf{\nabla}$ : Inpulsivity or agression, $\square$ : full compliance, $\triangle$ : partial compliance, $X$ : noncompliance. 
Table I Characteristics of cases and their outcomes

\begin{tabular}{|c|c|c|c|c|c|c|}
\hline Characteristics & Case I & & Case 2 & & Case 3 & \\
\hline Age (years) & 43 & & 38 & & 54 & \\
\hline Sex & Male & & Female & & Female & \\
\hline Diagnosis & BP I & & BP I & & BP II & \\
\hline Entry status & & & & & & \\
\hline MADRS & 4 & & 9 & & 9 & \\
\hline YMRS & 13 & & 15 & & 4 & \\
\hline Current status & & & & & & \\
\hline MADRS & 5 & & 8 & & 4 & \\
\hline YMRS & 2 & & 11 & & 5 & \\
\hline Number of episodes & I & & 2 & & 2 & \\
\hline Number of admissions & 0 & & 0 & & 0 & \\
\hline Mood $^{\mathrm{a}}$ & & & & & & \\
\hline Ist year & -0.50 & 45 & -0.76 & 48 & -0.51 & 40 \\
\hline 2nd year & -0.57 & 43 & -0.64 & 47 & -0.31 & 29 \\
\hline $3 r d$ year & -0.36 & 32 & -0.35 & 33 & -0.19 & 21 \\
\hline 4th year & -0.28 & 29 & -0.36 & 34 & -0.06 & 21 \\
\hline 5th year & -0.23 & 28 & -0.44 & 37 & -0.07 & 23 \\
\hline Motivation $^{\mathrm{a}}$ & & & & & & \\
\hline Ist year & -0.69 & 47 & -0.74 & 48 & -0.53 & 39 \\
\hline 2nd year & -0.68 & 44 & -0.69 & 44 & -0.42 & 35 \\
\hline $3 r d$ year & -0.32 & 31 & -0.37 & 34 & -0.12 & 26 \\
\hline 4th year & -0.30 & 32 & -0.39 & 36 & -0.17 & 26 \\
\hline 5th year & -0.23 & 25 & -0.41 & 33 & -0.11 & 22 \\
\hline Thinking speed ${ }^{a}$ & & & & & & \\
\hline Ist year & -0.91 & 57 & -0.67 & 47 & -0.58 & 44 \\
\hline 2nd year & -0.73 & 51 & -0.58 & 43 & -0.38 & 39 \\
\hline $3 r d$ year & -0.25 & 35 & -0.39 & 40 & -0.16 & 31 \\
\hline 4th year & -0.17 & 33 & -0.30 & 38 & -0.21 & 31 \\
\hline 5th year & -0.19 & 30 & -0.32 & 37 & -0.21 & 29 \\
\hline Impulsivity ${ }^{\mathrm{a}}$ & & & & & & \\
\hline Ist year & -1.32 & 82 & -1.81 & 62 & -1.81 & 51 \\
\hline 2nd year & -1.48 & 71 & -1.48 & 70 & -1.84 & 46 \\
\hline $3 r d$ year & -1.92 & 40 & -1.92 & 40 & -1.92 & 40 \\
\hline 4th year & -1.83 & 50 & -1.83 & 50 & -1.69 & 51 \\
\hline 5 th year & -1.93 & 34 & -1.93 & 34 & -1.80 & 41 \\
\hline
\end{tabular}

Notes: aData are shown as mean and CV using 365 points. CV was calculated by standard deviation divided by mean after transformation from -2 to 2 Likert scale to I to 5 Likert scale.

Abbreviations: BP, bipolar disorders; CV, coefficient of variation; MADRS, Montgomery and Asberg Depression Rating Scale; YMRS, Young Mania Rating Scale.

Her mood fluctuations decreased, and her mental state has remained relatively stable for more than 5 years. For work, she helped her parents at an apple farm. She has continued the self-monitoring daily mood charts for more than 6 years, and her mental state has remained stable (Table 1). She visits us at a 2-week interval.

\section{Case 3}

The patient was a 54-year-old Japanese female with a 3-year history of type II bipolar disorder with two admissions for a depressive state. She was treated with $800 \mathrm{mg} / \mathrm{d}$ of lithium and $0.25 \mathrm{mg} / \mathrm{d}$ of brotizolam. Because her mood swings were becoming too rapid, self-monitoring daily mood charts as described in Case 1 was initiated. In addition to selfmonitoring daily mood charts, wake-up time, bedtime, and medication checks were recorded. Her mood fluctuations decreased, and her mental state has remained stable for more than 5 years. She got married 2 years after initiating self-monitoring daily mood charts, and she does housework. She has continued the self-monitoring daily mood charts for more than 5 years, and her mental state has remained stable (Table 1). She visits us at a 4-week interval.

\section{Discussion}

The results of cases suggested that our paper-and-pencil form of self-monitoring daily moods was effective for preventing recurrence for bipolar disorders. We have maintained a stable mental condition for over 5 years using self-monitoring of daily mood in three cases, all of whom had a high risk of recurrence, although this number of subjects was very small and observation period was still short. We calculated the mean and coefficient of variation using 365 points (Table 1). Mood fluctuations decreased in all patients as the average score approached zero and coefficient of variation values decreased over time. As long-term treatment should be required for patients with bipolar disorder, our method of self-monitoring daily mood may be superior to current options in terms of utility and feasibility. Further studies are required to confirm the utility of our self-monitoring daily mood approach in larger samples.

Many studies have suggested that the main factors of recurrence in bipolar disorders are noncompliance and abnormal sleep-wake rhythms. ${ }^{10-12}$ Therefore, we added columns for wake-up time and bedtime and a medication check to the mood chart. In addition, we divided mood into four components, namely, mood, motivation, concentration or thinking speed, and impulsivity or aggression, because we aimed to capture the mixed futures of bipolar disorders based on mixed depression, as described by Kraepelin. ${ }^{13}$ Most patients with successful outcomes wrote detailed routine events as well as special events in the remarks section of the self-monitoring daily mood chart. This may be a positive occurrence, as it suggests that they looked back at themselves and their behaviors for that day. Weekly summaries of patients' data can be discussed with them so they gain insight into the contexts in which they feel better or worse and can adjust their behavior accordingly.

\section{Disclosure}

Norio Yasui-Furukori has received grant/research support or honoraria from and has been a lecturer for Asteras, 
Dainippon, Eli Lilly, GSK, Janssen-Pharma, Meiji, Mochida, MSD, Otsuka, Pfizer, Takeda, and Yoshitomi; none of the funders had a role in study design, data collection and analysis, decision to publish, or preparation of the manuscript. The authors report no other competing interests or conflicts of interest in this work.

\section{References}

1. Merikangas KR, Akiskal HS, Angst J, et al. Lifetime and 12-month prevalence of bipolar spectrum disorder in the National Comorbidity Survey replication. Arch Gen Psychiatry. 2007;64(5):543-552.

2. Nurnberger JL, Gershon ES. Genetics. In: Paykel ES, editor. Handbook of affective disorders. 2nd ed. New York, NY: Guilford Press; 1992: 131-148.

3. Johnson SL, Roberts JE. Life events and bipolar disorder, implications from biological theories. Psychol Bull. 1995;117(3):434-449.

4. Simon GE, Bauer MS, Ludman EJ, Operskalski BH, Unützer J. Mood symptoms, functional impairment, and disability in people with bipolar disorder: specific effects of mania and depression. J Clin Psychiatry. 2007;68(8):1237-1245

5. Schooler LJ, Hertwig R. How forgetting aids heuristic inference. Psychol Rev. 2005;112(3):610-628.
6. Bauer M, Glenn T, Grof P, et al. Self-reported data from patients with bipolar disorder: frequency of brief depression. $J$ Affect Disord. 2007; 101(1-3):227-233.

7. Bauer M, Wilson T, Neuhaus K, et al. Self-reporting software for bipolar disorder: validation of ChronoRecord by patients with mania. Psychiatry Res. 2008;159(3):359-366.

8. aan het Rot M, Hogenelst K, Schoevers RA. Mood disorders in everyday life: a systematic review of experience sampling and ecological momentary assessment studies. Clin Psychol Rev. 2012;32(6):510-523.

9. Proudfoot J, Whitton AE, Parker G, Manicavasagar V, Nicholas J, Smith M. Evidence of weekly cyclicity in mood and functional impairment in those with a bipolar disorder. Psychiatry Res. 2014;218(3): 290-294.

10. Malkoff-Schwartz S, Frank E, Anderson B, et al. Stressful life events and social rhythm disruption in the onset of manic and depressive bipolar episodes: a preliminary investigation. Arch Gen Psychiatry. 1998;55(8):702-707.

11. Altman S, Haeri S, Cohen LJ, et al. Predictors of relapse in bipolar disorder: a review. J Psychiatr Pract. 2006;12(5):269-282.

12. Scott J, Pope M. Self-reported adherence to treatment with mood stabilizers, plasma levels, and psychiatric hospitalization. Am J Psychiatry. 2002;159(11):1927-1929.

13. Kraepelin E. Manic-depressive Insanity and Paranoia. (Robertson GM, editor, Barclay RM, Translator). Edinburgh, Scotland: E \& S Livingstone 1921.
Neuropsychiatric Disease and Treatment

\section{Publish your work in this journal}

Neuropsychiatric Disease and Treatment is an international, peerreviewed journal of clinical therapeutics and pharmacology focusing on concise rapid reporting of clinical or pre-clinical studies on a range of neuropsychiatric and neurological disorders. This journal is indexed on PubMed Central, the 'PsycINFO' database and CAS,

\section{Dovepress}

and is the official journal of The International Neuropsychiatric Association (INA). The manuscript management system is completely online and includes a very quick and fair peer-review system, which is all easy to use. Visit http://www.dovepress.com/testimonials.php to read real quotes from published authors. 